\title{
Pengembangan E-Modul Berbasis Inkuiri Terbimbing Terintegrasi Laboratorium Virtual Pada Materi Sistem Koloid Kelas XI SMA/MA
}

\author{
F Febriyandi ${ }^{1}$ and Andromeda ${ }^{1 *}$ \\ ${ }^{1}$ Pendidikan Kimia, Universitas Negeri Padang, Jl. Prof. Dr. Hamka Air Tawar Barat, \\ Padang Utara, Sumatera Barat 25171, Indonesia \\ *andromedasaidir@gmail.com
}

\begin{abstract}
The type of research used is research and development or Research and Development (R\&D). The development model used is a 4-D model (four-D models) which consists of 4 stages, namely: define, design, develop and disseminate. This research is limited to the stage of development, namely the validity and practicality test. The research instrument used was a questionnaire of validity and practicality. The e-module was validated by 6 validators while the practicality test was carried out by 2 chemistry teachers and 20 XI grade students of MIPA SMAN 12 Padang and 20 XI grade students oh MIPA SMAN 2 Pariaman. Data from the validity and practicality test results were ana lyzed using the cohen kappa formula. Based on the results of the study, it was found that the average kappa moment of validity test was 0,87 with a very high validity category and the average kappa moment of teacher practicality was 0,88 , students of SMAN 12 Padang were 0,87 and students of SMAN 2 Pariaman were 0,88 with a very high practicality category. Thus, it was concluded that acid base e-module based on discovery learning was produced for valid and practical high school students.
\end{abstract}

\section{Pendahuluan}

Koloid adalah salah satu materi pokok mata pelajaran kimia kelas XI SMA yang diajarkan pada semester genap. Dalam materi sistem koloid banyak mengandung fakta, konsep-konsep, prosedur serta bersifat teoritis dan hafalan yang harus dikuasai oleh siswa. Contoh fakta yang terdapat pada materi sistem koloid adalah susu, asap, cat, agar-agar. Contoh konsep yang terdapat pada materi sistem koloid adalah pengertian sistem koloid, jenis-jenis koloid dan sifat-sifat koloid. Sedangkan contoh prosedurnya adalah proses pembuatan koloid. Materi sistem koloid banyak ditemukan dalam kehidupan sehari-hari seperti santan, kabut, susu, mentega, ice cream, buih, keju dan sebagainya. Sifat koloid digunakan dalam proses penjernihan air, proses penggumpalan pada lateksdan proses cuci darah bagi penderita ginjal[1].

Laboratorium virtual adalah media yang dapat digunakan untuk memahami suatu pokok bahasan dan dapat memberikan solusi terhadap keterbatasan atau ketiadaan perangkat laboratorium. Sehingga laboratorium virtual dapat membantu keterbatasan terlaksananya praktikum yang dilaksanakan secara nyata [2].

Berdasarkan hasil wawancara dan angket yang diberikan kepada 3 orang guru kimia dan 60 orang siswa SMA kelas XII diperoleh data bahwa: (a) ketersediaan bahan ajar yang digunakan belum mendukung siswa dalam menemukan konsep pada proses pembelajaran dikelas ataupun pada pelaksanaan praktikum sesuai dengan tuntutan kurikulum 2013, (b) bahan ajar yang digunakan guru kurang menarik perhatian. Oleh karena itu, perlu diberikan bahan ajar berupa e-modul yang dapat meningkatkan motivasi siswauntuk belajar secara mandiri dan menemukan konsep sendiri.

Kurikulum 2013 menuntut pembelajaran berbasis pendekatan saintifik. Salah satu model pembelajaran yang menerapkan pendekatan saintifik sesuai tuntutan kurikulum 2013 adalah pembelajaran berbasis inkuiri terbimbing. Inkuiri terbimbing merupakan pembelajaran yang melibatkan siswa secara langsung 
dalam proses pembelajaran melalui penyelidikan untuk menyelesaikan permasalahan yang diberikan oleh guru, kemudian siswa menentukan proses dan solusi dari permasalahan tersebut seingga siswa dapat membuat kesimpulan.Langkah-langkah pembelajaran inkuiri terbimbing terdiri dari 5 tahap yaitu orientasi, eksplorasi, pembentukan konsep, aplikasi dan penutup[3]. Untuk menemukan konsep siswa dipandu dengan serangkaian pertanyaan kritis (critical thinking question) yang dimulai dari pertanyaan sederhana hingga pertanyaan yang kompleks. Pertanyaan inilah yang akan dijawab oleh siswa setelah mengamati serta menganalisa video dan animasi pada tahap eksplorasi.

Penelitian yang dilakukan terkait laboratorium virtual diantaranya Hermansyah yang menyimpulkanbahwa penggunaan laboratorium virtual dapat meningkatkanpenguasaan konsep dan kemampuan berpikir kreatif siswa. Laboratorium virtual dapat dijadikanalternatif untuk tetap bisa melakukan eksperimen. Selain lebih murah dan terjangkau, juga lebih aman bagi siswa sebagai pengguna. Siswajuga dapat melakukan eksperimen dimanapun dankapanpun sesuai kebutuhannya [4]. Penelitian terkait e-modul berbasis inkuiri terbimbing telah dilakukan oleh Budiarti, dkk yang menyimpulkan bahwa dengan menerapkan model inkuiri terbimbing pada proses pembelajaran adapat meningkatkan keterampilan berfikir kritis siswa [5].Penelitian terkait modul system kolid telah dilakukan oleh Rahmah dan Andromeda, yang menyimpulkan bahwa pembelajaran menggunakan modul sistem koloid berbasis inkuiri terbimbing dapat meningkatkan hasil belajar siswa [6].

\section{Metode}

Jenis penelitian ini menggunakan penelitian dan pengembangan atau Research and Development (R\&D). Subjek penelitian ini adalah 4 orang dosen jurusan kimia FMIPA UNP, 2 orang guru kimia SMA dan 20 orang siswa kelas XII MIPA 1 SMAN 12 Padang dan 20 orang siswa kelas XII MIPA 5 SMAN 2 Pariaman. Objek penelitian ini adalah e-modul sistem koloid berbasis inkuiri terbimbing terintegrasi laboratorium virtual untuk siswa SMA. Model pengembangan yang digunakan pada penelitian ini adalah model 4-D (Four-D models) yang terdiri dari 4 tahap yaitu: (a) define (pendefinisian), (b) design (perancangan), (c) develop (pengembangan), (d) Dessiminate (penyebaran)[7].

Pada tahap define (pendefinisian) dilakukan penetapan syarat-syarat pembelajaran dengan menganalisis Kompetensi Inti, Kompetensi Dasar, dan bahan materi pembelajaran berdasarkan standard isi kurikulum 2013. Syarat-syarat yang ditetapkan tersebut dapat dilakukan melalui lima langkah pokok, sebagai berikut: (a) tahap analisis ujung depan dilakukan dengan wawancara dengan guru kimia; (b) analisis siswa dilakukan dengan penyebaran angket kepada siswa yang bertujuan untuk memahami karakteristik siswa; (c) analisis tugas dilakukan dengan menganalisis kompetensi dasar (KD) 3.14 dan 4.14 yang selanjutnya dilakukan perumusan indikator sesuai dengan KD tersebut; (d) analisis konsep dilakukan dengan cara mengidentifikasi konsep-konsep utama pada materi sistem koloid; (e) analisis tujuan pembelajaran dilakukan dengan pengubahan hasil analisis tugas dan analisis konsep ke dalam tujuan pembelajaran yang akan dicapai oleh siswa.

Pada tahap design (perancangan) bertujuan untuk merancang e-modul sistem koloid berbasis. Perancangan terdiri dari: cover, petunjuk belajar, kompetensi yang akan dicapai, lembar kegiatan, lembar kerja siswa, lembaran evaluasi, kunci jawaban, dan daftar pustaka.

Pada tahap develop (pengembangan) terdiri dari dua kegiatan yaitu uji validitas dan uji praktikalitas. Pada penelitian ini tahap dessiminate (penyebaran) dilakukan dalam skala yang kecil. Uji validitas dilakukan dengan memberikan angket validitas yang terdiri dari 4 aspek penilaian yaitu segi kelayakan isi, komponen penyajian,komponen kebahasaan dan komponen kegrafikaan kepada 6 orang validator yang terdiri dari 4 orang dosen kimia FMIPA UNP dan 1 orang guru kimia SMAN 12 Padang dan 1 orang guru kimia SMAN 2 Pariaman. Uji praktikalitas e-modul pembelajaran diperoleh melalui angket respon guru kimia SMAN 12 Padang dan SMAN 2 Pariaman dan siswa kelas XII MIPA 1 SMAN 12 Padang dan kelas XII MIPA 5 SMAN 2 Pariaman.

Instrumen pengumpulan data yang digunakan dalam penelitian ini adalah angket uji validitas dan praktikalitas yang diperoleh dan dianalisis menggunakan formula kappa cohen untuk menentukan tingkat validitas dan praktikalitas e-modul sistem koloid berbasis inkuiri terbimbing terintegrasi laboratorium virtual [8]. Angket uji validitas dan praktikalitas yang digunakan disusun berdasarkan skala Likert seperti pada Tabel 1: 
Tabel 1. Skala Likert

\begin{tabular}{c|c} 
Skala & Penilaian \\
\hline 1 & Sangat Tidak Setuju \\
\hline 2 & Tidak Setuju \\
\hline 3 & Netral \\
\hline 4 & Setuju \\
\hline 5 & Sangat Setuju
\end{tabular}

Data hasil uji validitas dan praktikalitas yang diperoleh dianalisis menggunakan formula kappa Cohenseperti di bawah ini:

momen $\operatorname{kappa}(k)=\frac{\rho_{0}-\rho_{e}}{1-\rho_{e}}$
Keterangan:
\begin{tabular}{c|c|c}
$\mathrm{K}$ & $=$ & momen kappa \\
\hline$\rho_{\mathrm{O}}$ & $=$ & Proporsi yang terealisasi \\
\hline$\rho_{e}$ & $=$ & Proporsi yang tidak terealisasi
\end{tabular}

Tabel 2. Kategori Keputusan Berdasarkan Momen kappa ( $k$ )[8]

\begin{tabular}{c|c} 
Interval & Kategori \\
\hline $0,81-1,00$ & Sangat Tinggi \\
\hline $0,61-0,80$ & Tinggi \\
\hline $0,41-0,60$ & Sedang \\
\hline $0,21-0,40$ & Rendah \\
\hline $0,01-0,20$ & Sangat Rendah \\
\hline$<0,00$ & Tidak Valid
\end{tabular}

\section{Hasil dan Diskusi}

\subsection{Tahap Pendefinisian}

3.1.1. Analisis Ujug Depan. Analisis ujung depan dilakukan dengan cara mewawancarai guru kimia. Berdasarkan hasil wawancara dan angket yang diberikan kepada 3 orang guru dan 60 siswa di SMAN 12 Padang, SMAN 2 Pariaman dan SMAN 2 Lubuk Basuang diperoleh data bahwa:(a)Belumterdapat bahan ajar dalam bentuk e-modulyang terintegrasi laboratorium virtual, (b) Ketersediaan bahan ajar yang digunakan belum mendukung siswa dalam menemukan konsep pada proses pembelajaran dikelas ataupun pada pelaksanaan praktikum sesuai dengan tuntutan kurikulum 2013, (c) Bahan ajar yang digunakan guru kurang menarik perhatian siswa.

3.1.2. Analisis Siswa. Analisis siswa dilakukan dengan pengisian angket oleh siswa SMAN 12 Padang, SMAN 2 Pariaman, dan SMAN 2 Lubuk Basuang. Siswa SMA dikategorikan sebagai remaja dengan usia 15-17 tahun. Berdasarkan teori perkembangan kognitif piaget siswa SMA dimulai dari usia 15-17 tahun termasuk ke dalam tahap operaional formal [9]. Tahap operasional formal ini ditandai dengan kemampuannya untuk berfikir secara abstrak, menalar secara logis dan menarik kesimpulan dari informasi yang tersedia.

3.1.3. Analisis Tugas. Berdasarkan silabus kurikulum 2013 materi sistem koloid terdapat pada KD 3.14 dan 4.14. KD 3.14Mengelompokkan berbagai tipe sistem koloid, menjelaskan sifat-sifat koloid dan penerapannya dalam kehidupan sehari-hari; dan KD 4.14Membuat makanan atau produk lain yang berupa koloid atau melibatkan prinsip koloid. Berdasarkan KD 3.14 dan 4.14 tersebut dirumuskan indikator pencapaian kompetensi (IPK) yaitu 1) Mengklasifikasikan larutan, koloid dan suspensi, 2) Mengelompokkan jenis koloid berdasarkan fase terdispersi dan medium pendispersi, 3) Menjelaskan 
sifat-sifat koloid (optik, kinetik, listrik, adsorpsi, koagulasi, dan dialisis), 4) Membedakan koloid liofob dan koloid liofil, 5) Menjelaskan proses pembuatan koloid di laboratorium, 6) Menganalisis peranan koloid dalam kehidupan sehari-hari dan 7) Melakukan proses pembuatan koloid dalam kehidupan sehari-hari dan Industri.

3.1.4. Analisis Konsep. Berdasarkan analisis konsep dapat ditentukan konsep-konsep utama yangakan dipelajari pada materi sistem koloid. Konsep-konsep utama pada materi sistem koloid terdiri dari: koloid, efek tyndall, gerak brown, adsorpsi, koagulasi, elektroforesis, dialisis, koloid liofil, koloid liofob, kondensasi dan dispersi. Konsep-konsep ini secara hirarki dituang dalam bentuk tabel analisis konsep.

3.1.5. Analisis Tujuan Pembelajaran. Berdasarkan IPK yang telah dirumuskan, dapat ditentukan tujuan pembelajaran. Tujuan pembelajaran materi sistem koloid adalah: melalui model model pembelajaran inkuiri terbimbing berbasis laboratorium virtual, diharapkan peserta didik terlibat aktif selama proses pembelajaran berlangsung, meningkatkan rasa syukur atas nikmat akal sebagai anugrah dari Tuhan Yang Maha Esa, memiliki sikap ingin tahu, telitidalam melakukan pengamatan dan bertanggung jawab dalam menyampaikan pendapat,menjawab pertanyaan, memberi kritik dan saran, dan dapat mengelompokkan berbagai tipe sistem koloid, menjelaskan kegunaan dalam kehidupanberdasarkan sifat-sifatnya, serta dapat membuat makanan atau produk lain yang berupa koloid atau melibatkan prinsip koloid.

\subsection{Tahap Perancangan}

Pada tahap perancangan ini dilakukan desain e-modul sistem koloid berbasis inkuiri terbimbing yang akan dikembangkan. E-modul ini disusun berdasarkan komponen-komponen e-modul yang terdiri dari: cover, petunjuk belajar, kompetensi yang akan dicapai, lembar kegiatan, lembar kerja siswa, lembaran evaluasi, kunci jawaban, dan daftar pustaka. Pada lembaran kerja disusun berdasarkan tahapan-tahapan inkuiri terbimbing.E-modul ini dibuat dengan menggunakan aplikasi Microsoft Publisher 2013, Adobe Flash CS6.

\subsection{Tahap Pengembangan}

3.3.1. Uji Validasi. Uji validitas adalah penilaian terhadap rancangan suatu produk atau bahan ajar. Aspek penilaian dibagi menjadi 4 komponen yang terdiri dari komponen isi, komponen kebahasaan, komponen penyajian, dan komponen kegrafikaan [10]. E-modul sistem koloid berbasis inkuiri terbimbingdiberi penilaian oleh 4 orangdosen kimia dan 2 orang guru kimia. Berdasarkan pengolahan data menggunakan moment kappa diperoleh hasil uji validitas seperti yang terlihat pada Tabel 3 .

Tabel 3. Hasil Analisis Data Uji Validitas

\begin{tabular}{c|c|c} 
Aspek yang Dinilai & $\mathbf{k}$ & Kategori \\
\hline Komponen Isi & 0,84 & Sangat tinggi \\
\hline Komponen Kebahasaan & 0,91 & Sangat Tinggi \\
\hline Komponen Penyajian & 0,83 & Sangat Tinggi \\
\hline Komponen Kegrafikan & 0,89 & Sangat Tinggi
\end{tabular}

Keterangan k = moment kappa

Komponen isi e-modul sistem koloid berbasis inkuiri terbimbing memiliki rata-rata momen kappa sebesar 0,84 dengan kategori sangat tinggi. Hal ini menunjukkan bahwa e-modul yang dikembangkan telah sesuai dengan Kompetensi Dasar (KD), yaitu KD 3.14 dan KD 4.14 pada Silabus Kurikulum 2013. Aspek komponen isi meliputi kesesuaian materi yang terdapat dalam e-modul dengan KI, KD dan tujuan pembelajaran yang ingin dicapai, materi yang diberikan sesuai dengan kemampuan siswadan pertanyaan-pertanyaan pada lembar kegiatan sesuai dengan materi yang dipelajari [11].

Komponen kebahasaan memiliki nilai rata-rata momen kappa e-modul sistem koloid berbasis inkuiri terbimbing yang dikembangkan sebesar 0.91 dengan kategori sangat tinggi. Hal ini berarti bahasa yang digunakan pada e-modul yang dikembangkan jelas dan telah sesuai dengan kaidah Bahasa Indonesia yang baik dan benar, komunikatif serta mudah dipahami. Penggunaan lambang atau simbol pada modul juga sudah konsisten. E-modul yang baik menggunakan kalimat yang sederhana sehingga informasi 
yang disampaikan jelas dan bersifat user friendly (bersahabat dengan pemakainya) [12].

Komponen penyajian memiliki nilai rata-rata momen kappa e-modul sistem koloid berbasis inkuiri terbimbing yang dikembangkan sebesar 0.83 dengan kategori sangat tinggi. Hal ini berarti e-modul sistem koloid berbasis inkuiri terbimbing yang telah dikembangkan dibuat sesuai dengan indikator dan tujuan pembelajaran yang telah dirumuskan. Penyajian e-modul disusun berdasarkan tahapan model inkuiri terbimbing. Pada tahapan tersebut terdapat gambar, video, animasi dan pertanyaan-pertanyaan yang berhubungan dengan materi yang dibahas. Hal ini bertujuan agar siswa lebih termotivasi dalam belajar serta untuk meningkatkan pemahaman siswa terhadap materi tersebut. Pada e-modul ini juga dilengkapi dengan soal evaluasi. Pada soal evaluasi, nilai siswa dapat dilihat langsung setelah menjawab semua pertanyaan- pertanyaan yang ada pada soal tersebut.

Komponen kegrafikan memiliki nilai rata-rata momen kappa e-modul sistem koloid berbasis inkuiri terbimbing yang telah dikembangkan sebesar 0.89 dengan kategori sangat tinggi. Hal ini menunjukkan bahwa e-modul asam sistem koloid berbasis inkuiri terbimbing yang dikembangkan memiliki lay out (tata letak), video, gambar, desain tampilan dan ukuran huruf dan jenis huruf secara keseluruhan sudah jelas dan menarik. E-odul yang dibuat semenarik mungkin dapat memotivasi peserta didik untuk membaca bahan materi dalam pembelajaran [13]. Pada e-modul juga dilengkapi dengan gambar-gambar yang mendukung materi sistem koloid. Penggunaan gambar dapat menambah daya tarik bahan ajar dan dapat mengurangi kebosanan siswa dalam proses pembelajaran. Selain itu juga terdapat video dan animasi yang relevan dengan materi yang disajikan. Ini berfungsi untuk meningkatkan pemahaman dan motivasi belajar siswa.

Secara keseluruhan e-modul sistem koloid berbasis inkuiri terbimbing yang telah dikembangkan memiliki tingkat kevalidan sebesar 0,87 dengan kategori sangat tinggi. Hal ini berarti e-modul sistem koloid yang dikembangkan sudah valid baik dari segi isi maupun segi konstruk. Hasil analisis e-modul pada uji validitas dapat dilihat pada Gambar 1.

\section{Hasil Uji Validitas E-Modul Sistem} Koloid oleh Validator

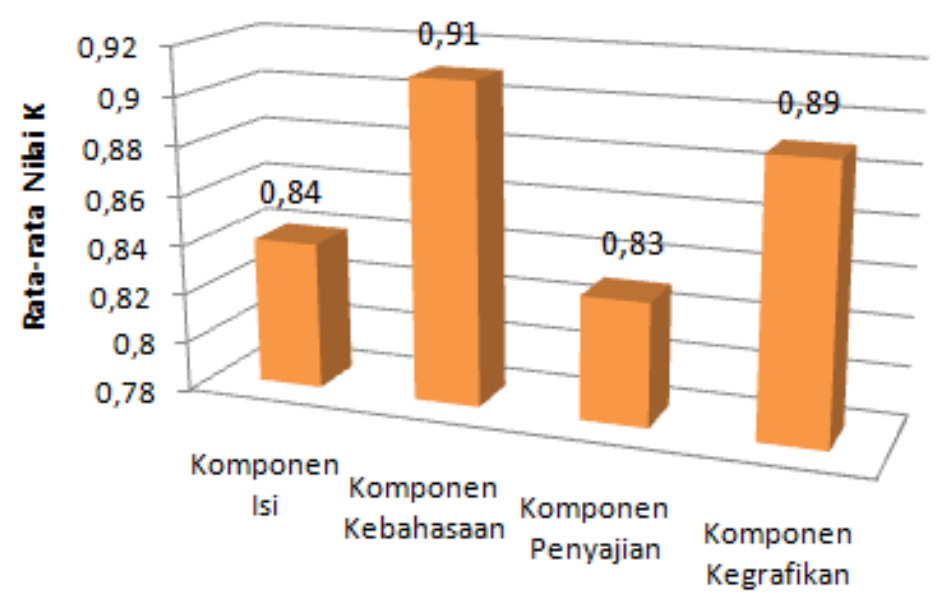

Komponen Yang Dinilai

Gambar 1. Hasil Analisis Data Uji Validitas

Hasil validasi yang diperoleh dari validator selanjutnya dilakukan beberapa revisi terhadap rancangan e-modul sistem koloid yang dikembangkan berdasarkan saran dari validator.

3.3.2. Revisi. Tahap revisi bertujuan untuk memperbaiki bagian e-modul sistem koloid berbasis inkuiri terbimbingyang dianggap kurang tepat oleh validator sebelum produk diuji coba. E-modul yang telah direvisi selanjutnya diberikan kepada validator untuk didiskusikan kembali. Revisi selesai apabila e-modul sistem koloid berbasis inkuiri terbimbingyang dikembangkan dinyatakan valid oleh validator. Beberapa komponen e-modul sistem koloid berbasis inkuiri terbimbingyang disarankan direvisi oleh validator: 1) sebaiknya dalam video larutan suspensi dan koloid dilengkapi partikel, 2) memperbaiki 
tahap eksplorasi dan pembentukan konsep , 3) memperbaiki animasi agar lebih akurat dan 4) video perlu dilengkapi tod untuk mempercepat atau memundurkan tayangan video.

3.3.3. Uji Praktikalitas. Kepraktisan e-modul sistem koloid berbasis inkuiri terbimbing yang telah dikembangkan dapat dilihat dari keterpakaian produk pada hasil uji coba terbatas di lapangan yang dilakukan oleh guru kimia SMAN 12 Padang dan SMAN 2 Pariaman serta 20 orang siswa SMAN 12 Padang dan 20 orang siswa SMAN 2 Pariaman. Guru kimia dan siswa diminta untuk mengisi angket praktikalitas yang berkaitan dengan kemudahan penggunaan e-modul, efisiensi waktu belajar menggunakan e-modul dan manfaat menggunakan e-modul. Hasil praktikalitas oleh guru serta siswa di SMAN 12 Padang dan SMAN 2 Pariaman dapat dilihat pada Tabel 4, Tabel 5 dan Tabel 6.

Tabel 4. Hasil Analisis Data Praktikalitas oleh Guru

\begin{tabular}{c|c|c} 
Aspek yang Dinilai & $\mathbf{k}$ & Kategori \\
\hline Kemudahan Penggunaan & 0,95 & Sangat tinggi \\
\hline Efisiensi Waktu & 0,82 & Sangat Tinggi \\
\hline Manfaat & 0,88 & Sangat Tinggi
\end{tabular}

Tabel 5. Hasil Analisis Data Praktikalitas oleh Siswa di SMAN 12 Padang

\begin{tabular}{c|c|c} 
Aspek yang Dinilai & $\mathbf{k}$ & Kategori \\
\hline Kemudahan Penggunaan & 0,90 & Sangat tinggi \\
\hline Efisiensi Waktu & 0,86 & Sangat Tinggi \\
\hline Manfaat & 0,87 & Sangat Tinggi
\end{tabular}

Tabel 6. Hasil Analisis Data Praktikalitas oleh Siswa di SMAN 2 Pariaman

\begin{tabular}{c|c|c} 
Aspek yang Dinilai & $\mathbf{k}$ & Kategori \\
\hline Kemudahan Penggunaan & 0,90 & Sangat tinggi \\
\hline Efisiensi Waktu & 0,87 & Sangat Tinggi \\
\hline Manfaat & 0,88 & Sangat Tinggi
\end{tabular}

Berdasarkan pengolahan data menggunakan momen kappa, secara keseluruhan e-modul sistem koloid berbasis inkuiri terbimbing memiliki tingkat kepraktisan sebesar 0,88 dari angket respon guru dengan kategori sangat tinggi. Kemudian tingkat kepraktisan dari angket respon siswa di SMAN 12 Padang sebesar 0,87 dengan kategori sangat tinggi dan 0,88 dari angket respon siswa di SMAN 2 Pariaman dengan kategori sangat tinggi. Hasil uji praktikalitas e-modul sistem koloid berbasis inkuiri terbimbing dapat dilihat pada gambar 2 .

Hasil Uji Praktikalitas Modul Sistem Koloid Oleh

Guru dan Slswa

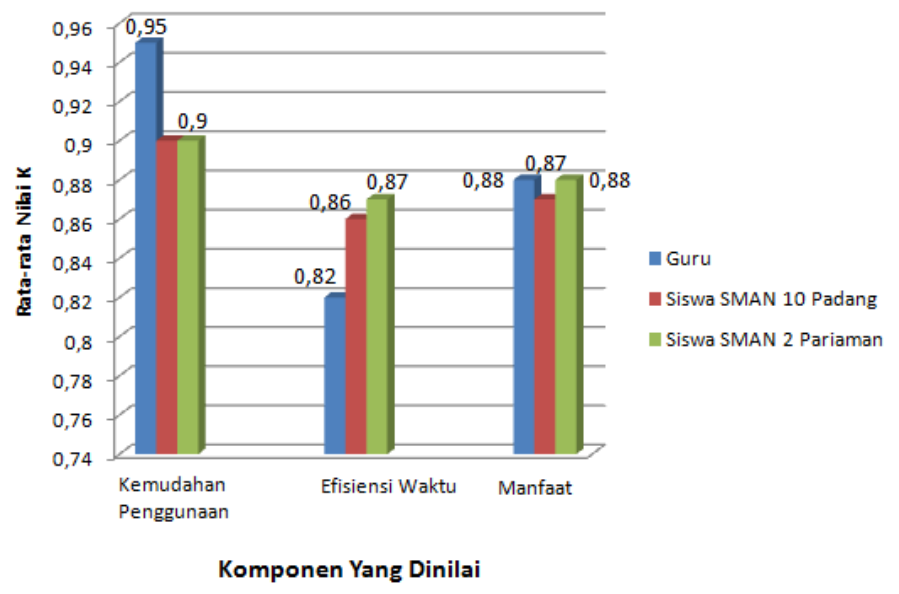

Gambar 2. Hasil Analisis Data Praktikalitas oleh Guru dan Siswa 


\section{Simpulan}

Berdasarkan penelitian yang telah dilakukan, dapat disimpulkan bahwa dihasilkan e-modul sistem koloid berbasis inkuiri terbimbing untuk kelas XI SMA/MA dengan model pengembangan 4-D. E-Modul yang dihasilkan mempunyai tingkat kevalidan dan kepraktisan sangat tinggi.

\section{Referensi}

[1] Kemendikbud. 2016. Silabus Mata Pelajaran Sekolah Menengah Atas/Madrasah Aliyah (SMA/ MA) Mata Pelajaran Kimia. Jakarta: Kementerian Pendidikan dan Kebudayaan Chang, Raymond. 2005. Konsep-konsep Inti Edisi 3 Jilid 1. Jakarta: Erlangga.

[2] Nirwana, Ratih Rizqi. 2011. Pemanfaatan Laboratorium Virtual Dan E-Reference Dalam Proses Pembelajaran Dan Penelitian Ilmu Kimia. Jurnal PHENOMENON, Vol 1, No : 115-123.

[3] Hanson, D. M. 2005. Designing Process-Oriented Guided-Inquiry Activities. In Faculty Guidedbook: A Comprehensive Tool For Improving Faculty Performance, ed. S. W. Beyerlein and D. K. Apple. Lisle, IL: Pacific Crest.

[4] Hermansyah, dkk, 2015. Pengaruh PenggunaanLaboratorium Virtual TerhadapPenguasaan Konsep dan KemampuanBerpikir Kreatif Siswa Pada MateriGetaran Dan Gelombang. JurnalPendidikan Fisika dan Teknologi.1(2): 98.

[5] Budiarti, S., Nuswowati, M., dan Cahyono, E. 2016.Guided Inquiry Berbantuan E-modul untuk Meningkatkan Keterampilan Berfikir Kritis. Jurnal of Innovative Science Education JISE 5 (2) 2016 .

[6] Rahma, Fatia. 2018. Pengaruh Penggunaan Modul Sistem Koloid Berbasis Inkuiri Terbimbing Terintegrasi Eksperimen dan Keterampilan Proses Sains Terhadap Hasil Belajar Siswa Kelas XI MIPA SMAN 5 Padang. Skripsi (Jurusan Pendidikan Kimia, FMIPA, Universitas Negeri Padang).

[7] Trianto. 2012. Model Pembelajaran Terpadu: Konsep, Strategi, dan Implementasinya dalam Kurikulum Tingkat Satuan Pendidikan (KTSP). Jakarta: Bumi Aksara.

[8] Bouslaugh S. dan Watters P., A,. (2008). "Statistics in a Nutshell, a Desktop Quick Referance". United State of America: O’Reilley Media, Inc.

[9] Omrod, J. 2014. Psikologi Pendidikan Edisi ke-Enam. Jakarta: Erlangga.

[10] Depdiknas. 2008. Panduan Pengembangan Bahan Ajar. Jakarta: Departemen Pendidikan Nasional Direktorat Jenderal Manajemen Pendidikan Dasar dan Menengah Direktorat Pembinaan Sekolah Menengah Atas.

[11] Purwanto, Ngalim. 2006. Prinsip-Prinsip dan Teknik Evaluasi Pengajaran. Jakarta: Remaja Rosdakarya.

[12] Lasmiyati. 2014. Pengembangan Modul Pembelajaran untuk Meningkatkan Pemahaman Konsep dan Minat SMP.Jurnal Pendidikan Matematika. Volume 9, Nomor 2, Halaman 161-174.

[13] Lestari, Eka. Dan Abdur Rahman As'ari. A.R. 2013. Pengembangan Modul Pembelajaran Soal Cerita Matematika Kontekstual Berbahasa Inggris untuk Siswa Kelas X. Artikel. Malang: Universitas Negeri Malang. 